\title{
Perceived Social Support and Academic Engagement
}

\author{
L. C. H. Jayarathna \\ Department of Commerce \& Financial Management, Faculty of Commerce \& \\ Management Studies, University of Kelaniya, Sri Lanka \\ lakmali@kln.ac.lk/lakmali_j@yahoo.com
}

\begin{abstract}
When students switch to higher education, they experience substantial stress and declines in performance in academic works. Perceived social support is supposed to improve academic performance by reducing stress. This study examined the influence from perceived social support of the management undergraduates in Sri Lanka on their academic engagement level. Participants include first year management undergraduates in five selected state universities in Sri Lanka. Adapted scales based on student engagement scale of NSSE and multidimensional scale of perceived social support was used as the measuring instruments. According to the findings, in Sri Lanka also social support plays a significant role in the level of academic engagement of a first year undergraduate. Furthermore, out of three aspects identified on social support social support from family and friends were significantly affecting to the undergraduates' academic engagement level but not the social support from a significant other. Hence, as per the prior scholars' findings, undergraduates perceive that their social support level as a supportive factor for their academic works. It may cause to reduce their stress raised due to the significant change from school to university at the very first time period.
\end{abstract}

Keywords: Academic engagement, Social Support, Stress

\section{Background}

Traditionally, social support was considered as the exchange of verbal and nonverbal messages related to information of emotion transmitted to help to reduce individual's stress or uncertainty (Reis, 1990 cited in Wang, 2012). Academic engagement can be identified as the amount of time and effort that students spend on educational activities that are related to college academic work (Kuh, 2009). According to Mackinson (2011), effects of social support on academic engagement is critical to the design and implementation of 
involvements which have the potential to significantly improve the mental health, social, and education outcomes for adolescents. At the same time, scholars demonstrated that social support mainly from teachers and parents is a very important influence on adolescents as they progress from elementary school to higher education (Klem \& Connell, 2004). Teachers can convey a sense of caring, respect, and appreciation for their students that can be emphasized in a strengths-based intervention to promote their school achievement and engagement. Also peer support fulfills need for friendship and helps them to develop a sense of satisfaction with school. Receptive parental support can promote pre social behavior in school and increase academic motivation. Similarly, Jenson (2011) also revealed that, social support and family matter greatly in the student's retention and successful college experience in higher education. According to Folkman, et al., (1986) social support is positively correlated with academic achievement in adolescents and emerging adults.

\section{Purpose of the Study}

Mitchell and Zimet (2000) identify three aspects of perceived social support as social support from family, friends and significant others. According to Wentzel (1994) pursuit of academic responsibility goals of students significantly related with the peer support and teachers support. Hence adult students are coping with high stress when they are transferring to higher education; social support plays a significant role to decrease the stress to enhance the academic engagement. In this study researcher examine the relationship between social supports and academic engagement of first year management undergraduates according to the multidimensional scale of perceives social support. Since first year undergraduates are the most recently transferred student category from elementary school to higher education they may feel the higher stress in academic works in which social support makes more demand. Therefore, the purpose of the study was to examine the relationship between academic engagement of first year management undergraduates and their social support from family, friends and significant others. 


\section{Methodology}

\subsection{Participants}

The target population of the present study is the first year management undergraduates of Sri Lankan state universities. Thus, 15 state universities under the university grant commission, Sri Lanka are representing the population group of the study and there were around 1400 total number of first year undergraduates who fall into commerce and management category in the 2011/2012 academic year (UGC 2012) in which the present study was taken place. Simple random sampling technique was applied in the present study under the probability technique approach. Accordingly, 85 first year management undergraduates were participated as the respondents of the study representing five selected state universities. A structured questionnaire was used under a survey type study for data collection purpose.

\subsection{Instruments \& Measures}

The aim of the study was to examine the relationship between academic engagement and social support from the family, friends and significant others. National Survey of Student Engagement (NSSE) scale was the base instrument used to develop the measurements of academic engagement in the study, which was the most used and applied scale in the student engagement context (Carini, 2006). The NSSE scale was specifically designed to assess the extent to which students are engaged in empirically derived good educational practices and what they gain from their college experience (Pascarella, 2005). Also an adaptive scale of multidimensional scale of perceived social support was used to measure the perceived social support level of the students. All the measurements were tested for validity and reliability and applied the corrective actions before applying in the real study.

\subsection{Data Analysis}

The present study is fall into quantitative research design, hence the researcher had to select statistical methods to achieve the stated research objectives through the quantitative data analysis techniques. For the statistical analysis, SPSS version 20 software were used. Consequently, in order to profiling the respondents in the study, descriptive statistics; 
frequencies, percentages and pie charts were applied in the study. Then to address main objective of the study which is to examine the relationship between academic engagement and social support, standard multiple regression analysis applied in the study.

\section{Results}

Sixty five percent of those who took the survey were female and $35 \%$ were male and more than $80 \%$ of students were Sinhala and Buddhist. Majority of students have represented high level of social support scale which was range from 49 degree to 60 degree, under the multidimensional social support scale. Also majority of the respondent undergraduates achieved the higher level of academic engagement and no one shows the lower level of academic engagement category. Accordingly, $85 \%$ of students represent the high level and the rest $15 \%$ represent the moderate level of academic engagement. The results indicate that the average respondent has achieved the high level of academic engagement.

To measure the proportion of variance in academic engagement of a management undergraduate with the determinants of social support from friends, family and significant others for the student, a standard multiple regression analysis was performed. Prior to the analysis the assumptions under the regression analysis were tested. Accordingly, predictors of the model successfully met the requirement for serial correlation under the Durbin Wotson values. The DB value of 1.9 depicted that the predictors act independently. Multicollinearity tested with tolerance values and it was confirmed that predictors are not correlated. Since the values were plotted along with the diagonal in Normal P-P plot, it was confirmed that the variations of residuals of the predictors are normally distributed. Furthermore, since Maximum Mahalanobis Distance value (14.457) did not exceed the critical chi-sqaure value (16.266) it was confirmed that multivariate outliers are not existed in the model.

Notably, the overall model fit was satisfied with 5\% significant level, hence all three types of social support can be accountable for changing the academic engagement level of a management undergraduate. Addressing the purpose of the study, academic engagement was significantly correlate with the social support from family and friends but not with the social support from significant others. Accordingly, both social support from family 
$(\mathrm{p}=0.59, \mathrm{p}=.004)$ and social support from friends $(\mathrm{p}=0.14 \mathrm{p}=.007)$ positively correlate with academic engagement level of the first year management undergraduates. Nevertheless, social support from significant others was not significantly correlate with the academic engagement level of the first year management undergraduates.

\section{Conclusion}

It is typically assumed that social support improves the academic achievement of adolescents. These assumptions are based on prior theory (e.g., Lakey, 2000). Scholars believe that the social support for a particular student who recently moved from school to higher education can affect to overcome the stress they got due to the environmental change. Also authors have showed that peer support, parents' support and teachers' support have an important role in students' works in higher education (Wang \& Eccles, 2012).

Thus, same as the scholar's findings perceived social support significantly relate with the academic engagement of undergraduates in Sri Lanka as well. Hence the university provides differentiated tasks to fulfill rather than the school, to ready to fit with those students need to have a better relationships. Peer support fulfills youths' need for friendship and helps them to develop of sense of satisfaction with university. The groups of peers can satisfy their need for affection, sympathy and understanding of inner thoughts in a place where ideas are experimented and independence is valued. Parental support can promote pre-social behavior in university specially in beginning time and increase academic motivation. Parent can tend to lower the risk of troublesome and antisocial behavior in the very first time in higher education. On the other way around first year undergraduates do not see the relationship or support from any significant others as important to their academic works in the higher education.

\section{References}

Alberta, 2011. Student Engagement. [Online] Available at: https://education.alberta.ca/teachers/aisi/themes/student-engagement.aspx [Accessed 13 January 2014]. 
Allen, S. W., 2011. Facebook Intensity Scale: How do you measure up?. [Online] Available at: http://westallen.typepad.com/idealawg/2011/06/facebook-intensityscale-how.html [Accessed 27 January 2013].

Appleton, J., Christenson, S., Kim \& Reschly, A., 2006. Measuring cognitive and psychological engagement: Validation of the Student Engagement Instrument. Journal of School Psychology, Volume 44, pp. 427-445.

Bentler, P. \& Bonnet, D., 1980. Significance Tests and Goodness of Fit in the Analysis of Covariance Structures. Psychological Bulletin, 88(3), pp. 588-606.

Brint, S., Cantwell, A. M. \& Hanne, R. A., 2008. The Two Cultures of Undergraduate Academic Engagement. Research in Higher Education, 49(5), pp. 383-402.

Carini, R. M., D. Kuh, G. \& Klein, S. P., 2006. Student Engagement and Student Learning: Testing the Linkages. Research in Higher Education, 47(1), pp. 1-32.

Carini, R. M. D. K. G. \&. K. S. P., 2006. Student Engagement and Student Learning: Testing the Linkages. Research in Higher Education. Journal of Student Development, 47(1), pp. 1-32.

Chowdhury, M., 2006. Students' Personality Traits and Academic Performance: A FiveFactor Model Perspective. College Quarterly, Summer .

Folkman, Susan, Lazarus, R. S. \& Dunk, C., 1986. Dynamics of a stressful encounter: cognitive appraisal, coping, and encounter outcomes. ournal of personality and social psychology, 50(5).

Junco, R., 2011. Too much face and not enough books: The relationship between multiple indices of Facebook use and academic performance. Computers in Human Behavior, pp. 1-18. 
Klem, A. M. \& Connell, a. P., 2004. Relationships Matter: Linking Teacher Support to Student Engagement and Achievement. Journal of School Health, 74(7), p. 262273.

Krishnaswamy, K. N., Sivakumar, A. L. \& Mathirajan, M., 2006. Management Research Methodology, Integration of Principles, Methods and Techniques. New Delhi, India: Dorling Kindersly (India) Pvt Ltd.

Kuh, G. D., 2009. What student affairs professionals need to know About Student Engagement. Journal of College Students Development, 50(06).

Lakey, B. \&. C. S., 2000. Social support theory and measurement. In: Social support measurement and intervention. s.1.:New York: Oxford University Press., pp. 2952.

Lynch, J. G., 2012. Perceived Stress and the Buffering Effect of Perceived Social Support on Facebook, Keene, New Hampshire: s.n.

Mackinnon, S. P., 2011. Perceived Social Support and Academic Achievement:Crosslagged Panel and Bivariate Growth Curve Analyses. Journal of Youth and Adolescence, 41(5), pp. 474-485.

Newmann, F. M., 1992. Student Engagement and Achievement in American Secondary Schools.. s.1.:Center on Organization and Restructuring of Schools,Madison, WI.; National Center on Effective Secondary Schools, Madison, WI..

Pascarellaa, E. T., Seifertb, T. A. \& Blaich, C., 2010. How Effective are the NSSE Benchmarks in Predicting Important Educational Outcomes?. The Magazine of Higher Learning, 42(1), pp. 16-22.

Pascarella, E. \&. P., 2005. How college affects students. In: Athird decade of research. San Francisco. s.1.:San Francisco: Jossey. 
Pascarella, E. \& Terenzini, P., 2005. How college affects students: Athird decade of research. San Francisco. 02 ed. San Francisco: Jossey Bass.

Reynol Junco, 2011. The relationship between frequency of Facebook use, participation in Facebook activities, and student engagement. Computers \& Education, pp. $162-171$.

Sawir, E. et al., 2008. Loneliness and International Students: An Australian Study. Journal of Studies in International Education, 12(2), pp. 148-180.

Wang, M. T. \& Eccles, J. S., 2012. Social support matters: Longitudinal effects of social support on three dimensions of school engagement from middle to high school. Child Development, s.1.: s.n.

Wentzel, K. R., 1994. Relations of social goal pursuit to social acceptance, classroom behavior, and perceived social support. Journal of Educational Psychology, Volume Vol 86(2), pp. 173-182.

Wood, S. A. \& Hampson, S. E., 2005. Measuring the Big Five with single items using a bipolar response scale. European Journal of Personality, Volume 19, pp. 373390. 